\title{
De sujeito a colaborador: a privação dos direitos das juventudes na era da liberdade neoliberal
}

Rocheli Koralewski ${ }^{1}$

Gabriel Tamanchieviz Argenton ${ }^{2}$

\begin{abstract}
Resumo:
Neste estudo é analisada a noção de liberdade difundida pelo neoliberalismo nas juventudes. A pluralidade de contradições que reverbera a partir da lógica do empreendedorismo, em vez de conceber a promessa de autonomia financeira, gera uma massiva privação de direitos sociais. Desde 2013, com a promulgação do Estatuto da Juventude (Lei 12.852), são previstas garantias que deveriam balizar ações do poder público no intuito de promover dignidade às pessoas de 15 a 29 anos. Todavia, mesmo compreendidas como sujeitos de direitos, os(as) jovens experienciam uma condição juvenil marcada pela expansão de graves problemas estruturais. Assim, os discursos que impactam as juventudes são baseados no individualismo e na meritocracia: juntos geram uma sensação de liberdade que ocasiona uma superexploração. A construção de alternativas que valorizam a coletividade é uma forma de transgredir os valores neoliberais e construir uma liberdade que seja comungada por todas e todos.
\end{abstract}

\section{Palavras-chave:}

Juventudes. Neoliberalismo. Privação de direitos.

\section{From subject to collaborator: the young rights' disenfranchisement in the neoliberal freedom era}

\begin{abstract}
This study analyzes the notion of freedom disseminated by neoliberalism in youth. The plurality of contradictions that reverberates from the logic of entrepreneurship, instead of conceiving the promise of financial autonomy, generates a massive deprivation of social rights. Since 2013, with the promulgation of the Youth Statute (Law 12,852), guarantees have been provided that should guide actions by the government in order to promote dignity to people aged 15 to 29. However, even though they are subjects of rights, young people experience a youth condition marked by the expansion of serious structural problems. Thus, the discourses that impact youth are based on
\end{abstract}

1 Graduanda em Ciências Sociais na Universidade Federal da Fronteira Sul (UFFS) - Campus Erechim (RS). Secretária liberada da Pastoral da Juventude da Diocese de Erexim para o triênio 2019-2021. E-mail: rochelii_k@hotmail.com. ORCID iD: http://orcid.org/0000-0002-2806-0844.

2 Graduando do Curso Interdisciplinar em Educação do Campo: Licenciatura em Ciências das Natureza, na Universidade Federal da Fronteira Sul (UFFS) - Campus Erechim (RS). E-mail: argentonpoa@gmail.com. ORCID iD: http://orcid.org/0000-0003-4867-2386. 
individualism and meritocracy: together they generate a sense of freedom that causes overexploitation. The construction of alternatives that value the community is a way to transgress neoliberal values and build a freedom that is shared by all.

Keywords: Youth. Neoliberalism. Disenfranchisement.

\section{De sujeto a colaborador: la privación de los derechos de los jóvenes en la era de las libertades neoliberales}

Resumen: En este estudio se analiza la noción de libertad que difunde el neoliberalismo en la juventud. La pluralidad de contradicciones que reverberan desde la lógica del emprendimiento, en lugar de concebir la promesa de autonomía financiera, genera una privación masiva de derechos sociales. Desde 2013, con la promulgación del Estatuto de la Juventud (Ley 12.852), se brindan garantías que deben orientar las acciones del gobierno para promover la dignidad de las personas de 15 a 29 años. Sin embargo, a pesar de ser entendidos como sujetos de derechos, los jóvenes viven una condición de juventud marcada por la expansión de graves problemas estructurales. Así, los discursos que impactan a la juventud se basan en el individualismo y la meritocracia: juntos generan un sentido de libertad que provoca la sobre explotación. La construcción de alternativas que valoren a la comunidad es una forma de transgredir los valores neoliberales y construir una libertad compartida por todos.

Palabras clave: Juventud. Neoliberalismo. Privación de derechos.

"A liberdade é como o sol.

É o bem maior do mundo."

Jorge Amado

\section{Juventudes que ocupam espaços públicos}

Sob a lua, num banco nada confortável da praça, os jovens dormem. Essa poderia ser uma releitura literária de Capitães de Areia de Jorge Amado, mas é apenas a realidade de jovens que passam as noites sobre os bancos nada confortáveis das praças da capital paulista para garantir as doze horas de trabalho como entregadores de aplicativos ao raiar do dia ${ }^{1}$. Freelas, jobs e bicos constituem o cotidiano de grande parte das milhões de pessoas que se encontram na faixa etária dos 15 aos 29 anos e são categorizadas como jovens, segundo o Estatuto da Juventude².

Ao longo da história, diversas organizações juvenis foram marcadas pelo verbo "ocupar". Desde o século XIX, com o movimento abolicionista; os(as) estudantes do movimento estudantil na década de 1960; os(as) resistentes jovens da Ação Católica Especializada ${ }^{3}$ que se opunham às articulações de cunho espiritualista que foram alargadas no período da Ditadura Civil-Militar

\footnotetext{
1 "Dormir na rua e pedalar 12 horas por dia: a rotina dos entregadores de aplicativos". Reportagem de Leandro Machado publicada pela BBC News Brasil em 2019. Disponível em: https://www.bbc.com/portuguese/brasil-48304340?ocid=socialflow_facebook. Acesso: 16 jan. 2021. 2 Lei no 12.852 de 5 de agosto de 2013. Disponível em: http://www.planalto.gov.br/ccivil_03/_ato2011-2014/2013/lei/l12852.htm. Acesso em: 16 jan. 2021.

3 Segundo Sofiati (2018), a Ação Católica Especializada era formada pelas juventudes da JAC (agrária), JEC (estudantil), JIC (independente - mulheres de classe média), JOC (operária) e JUC (universitária).
} 
(SOFIATI, 2008): os(as) jovens se mobilizavam no intuito de promover as suas pautas juntamente com outros grupos que também ansiavam por transformações na sociedade. A partir dos anos 1980, esse contexto sofreu algumas modificações: as tribos ${ }^{4}$ urbanas constituídas pelos Punks e Darks (ABRAMO, 1994) cultivaram "[...] novas perspectivas de participação social e política" (SOFIATI, 2008, p. 03) que se distanciaram dos partidos e sindicatos, é nesse momento que foram criados o Movimento Cultural Hip-Hop e a Pastoral da Juventude do Brasil, por exemplo. Dos espaços que reivindicavam a abolição da escravatura, passando pelas escolas, movimentos classistas e as Igrejas: muitos espaços foram "ocupados" pelas juventudes 5 .

O neoliberalismo ${ }^{6}$ materializou o individualismo como regra. Ao pensar juventudes, é primordial perceber que esse contexto também influenciou a condição juvenil da época e gerou grandes mudanças nas formas de organização. Nesse sentido, Sofiati (2008, p. 03) relata que "a juventude dos anos 1990 é uma geração individualista: não "abre mão" dos seus desejos". Contudo, o autor destaca outras experiências que fizeram um contraponto a essa realidade, como é o caso dos "caras pintadas" e da juventude do Movimento dos Trabalhadores Sem Terra (MST), "[...] considerado como um dos únicos movimentos sociais que resistiram ao estabelecimento do neoliberalismo no Brasil" (SOFIATI, 2008, p. 03). A grande promessa de que o "[...] "bolo ia crescer" em nome do sacrifício coletivo da sociedade" (BAPTISTA, 2008, p. 95) não passou de uma grande fantasia que gerou profundas consequências negativas.

Tatiane Baptista (2008, p. 97) argumenta que "[...] o Estado neoliberal afirmou um processo de retrocesso em relação ao que se conquistou em 1988, jogando a sociedade no agravamento da pobreza, do desemprego, da violência, da insegurança, do medo, e, com isso um alto grau de conflito e violência.", portanto, as tensões local-global e as incertezas desse tempo histórico passaram a ser vividas de forma mais intensa entre as juventudes. Para Regina Novaes, em entrevista ao Instituto Humanitas Unisinos, "nunca houve tanta integração globalizada e nunca foram tão agudos os processos de exclusão" (IHU, 2019). Pode-se perceber, a partir desse contexto, que a juventude é um dos grupos mais vulnerabilizados, sendo uma grande vítima do sistema neoliberal: são os(as) mais desempregados(as), não dispõe de permanência nas instituições de ensino - apesar de todo o regozijo referente à universalização da educação básica -, são os que superlotam os cárceres e também os que mais morrem. Há, em curso, uma guerra contra a juventude que mesmo não sendo silenciosa é ouvida por ínfimas pessoas.

O curso da história ora rompeu ora cultivou modelos sobre as noções de juventude no contexto brasileiro. A primeira abordagem compreendia a juventude como "período preparatório", apenas como uma etapa de transição da infância à vida adulta; passando a entendê-la como uma "etapa problemática", como se a delinquência e a violência fossem inerentes à categoria e o desfecho ideal fosse o controle e o cerceamento; às recorrentes e altas expectativas vieram do entendimento de jovem "como ator estratégico do desenvolvimento", ou seja, como se a salvação do planeta fosse sua responsabilidade integral; até a noção que vigora hoje: a juventude "cidadã como sujeito de direitos" (ABRAMO, 2005). Cada modelo foi protagonista na condução da forma como os(as) jovens eram

\footnotetext{
4 Magnani (1992, p. 49) propõe uma reflexão à utilização do termo tribos argumentando que "não deixa de ser sintomático o fato de se tomar emprestado um termo usual no estudo das sociedades de pequena escala para descrever fenômenos que ocorrem em sociedades contemporâneas altamente urbanizadas e densamente povoadas". Para ele, "tribos urbanas" não vão além do nível da metáfora. 5 Abramovay e Esteves (2004, p. 22) argumentam o porquê do termo ser utilizado no plural. Segundo elas há, linhas da sociologia da juventude: "Outra, de caráter mais difuso, que, em função de reconhecer a existência de múltiplas culturas juvenis, formadas a partir de diferentes interesses e inserções na sociedade (situação socioeconômica, oportunidades, capital cultural etc.), define a juventude para muito além de um bloco único, no qual a idade seria o fator predominante. Por essa linha, vem se tornando cada vez mais corriqueiro o emprego do termo juventudes, no plural, no sentido não de se dar conta de todas as especificidades, mas, justamente, apontar a enorme gama de possibilidades presente nessa categoria.".

60 neoliberalismo é classificado como uma teoria político-econômica que faz uma releitura do liberalismo clássico para a modernidade. Seu princípio está na Europa pós-guerra, como resposta contrária ao modelo dos estados de bem-estar social e ao socialismo, correntes teóricas que previam intervenções maiores do Estado em diversos âmbitos, como por exemplo na regulamentação da economia e na execução de programas sociais (GENTILI; SADER, 1995).
} 
abordados(as) pela sociedade e é por isso que a maioria das políticas públicas zela pela tutelagem em vez de promover autonomia. Mesmo que, juntamente com a emancipação, ela esteja citada como um dos princípios da Lei no 12.852 que instituiu o Estatuto da Juventude.

A diversidade de experiências, processos de significação e contextos sociais gera situações juvenis que colaboram na construção de uma condição juvenil (ABRAMO, 2005). Ser jovem não se limita aos dois algarismos que constituem a idade", tendo em vista que a condição juvenil é "[...] vivida pelos jovens concretos a partir dos recortes de gênero, classe, etnia, por exemplo" (OLIVEIRA; TRANCOSO, 2016). Atravessados pelas consequências negativas do neoliberalismo, os jovens de carne e osso que vivenciam sua situação juvenil no século XXI seguem "ocupando" espaços públicos: mesmo sendo considerados cidadãos, sujeitos de direitos, alguns dormem na praça ou viram as noites dos finais de semana para serem entregadores de aplicativos. É o caso da reportagem publicada na BBC News Brasil:

Em Pinheiros, Gabriel de Jesus, 22, diz já ter virado o fim de semana trabalhando, também. 'Sábado à noite a gente dorme na praça Victor Civita. Não vale a pena voltar para casa e depois vir para cá de novo, de manhã', diz. Seu amigo, Robert dos Santos, completa: 'A gente reveza: um dorme no banco e outro fica acordado para proteger dos 'roubos'. (MACHADO, 2021).

Através do relato anterior é possível constatar que o sistema condiciona os(as) jovens a "ocuparem" espaços precários para sobreviverem em condições subumanas. As consequências das ruínas do neoliberalismo ocupam nossos corpos, tentam cercear as nossas mentes e arrancam o nosso direito de sonhar. Diante disso, o presente artigo propõe a problematização da noção de "juventude como sujeito de direito" em um contexto que, mesmo legalmente amparadas pelo Estatuto da Juventude, os sujeitos juvenis são subordinados(as) a uma prisão que confina o Artigo 6o da Constituição Federal e restringe a cidadania. Tudo em troca de uma ilusória flexibilização de horários e o paradoxal tratamento empoderado de "autônomo".

\section{A livre prisão dos sonhos neoliberais}

Diferente das juventudes dos anos 1970, que prezavam por ideais coletivos, os sonhos que mobilizam os(as) jovens do século XXI, em grande parte, são individualistas. Com o advento das políticas neoliberais, a liberdade se tornou um dos grandes desejos que acompanha a construção dos projetos de vida, isto é,

Um elemento predominante no discurso dos jovens quando pensam seu futuro e os desafios do cotidiano é o individualismo e a lógica do 'indivíduo-empresa'. Além de buscar empregos formais e/ou fazer 'bicos' (pequenos trabalhos inconstantes e temporários), também recorrem à saída pelo 'empreendedorismo' - sonho de 'ser seu próprio patrão' -, que se coloca como uma certa rebeldia frente aos trabalhos que lhes são apresentados e uma leitura liberal do mercado de trabalho, em que somente o esforço garante o 'sucesso'. (TRI CONTINENTAL, 2020).

A lógica meritocrática ${ }^{8}$ que conduz a trajetória dos "indivíduos-empresa" cria uma falsa sensação de liberdade, na qual os direitos são renunciados em troca da informalidade que

\footnotetext{
7 “Andrade (2007, p. 9) aborda a juventude como uma experiência etária específica, no sentido de que há uma idade ou uma temporalidade juvenil e "ser jovem é uma condição particular, mas não homogênea [...]: existem várias juventudes vivendo esta experiência etária que se relaciona com diferentes formas de sociabilidade" (OLIVEIRA; TRANCOSO, 2016, p. 285).

8 Barbosa (2014, p. 82) afirma que "o cerne do discurso meritocrático é a importância atribuída ao valor do reconhecimento dos resultados individuais. [...] Nesse discurso, a meritocracia é um estímulo, um instrumento para se fazer mais e melhor. Esse estímulo não é só pecuniário, mas é, também, simbólico. As pessoas sentem-se recompensadas pelos esforços despendidos e gratificadas pelo seu reconhecimento público".
} 
acentua as extensivas jornadas. É indiscutível que as relações trabalhistas formais necessitam passar por reformulações e que não contemplam o acelerado número de novas ocupações que irrompem com o avanço tecnológico. Porém, quando subordinados à lógica do empreendedorismo, observa-se que "[...] se configura como forma oculta de trabalho assalariado e que permite o proliferar das distintas formas de flexibilização salarial, de horário, funcional ou organizativa." (ANTUNES, 2012, p. 411). Dessa forma, são gerados novos empreendedores "livres" presos aos antigos dilemas do sistema capitalista.

Além de exigir mais mercado em detrimento de menos Estado, as convicções neoliberais atravessam os indivíduos e "[...] incidem novas racionalidades e práticas de governo da conduta que prezam não apenas liberdade, mas também autonomia, performance, flexibilização, empreendedorismo e responsabilização individuais" (SALGADO, 2013, p. 196). Cada um desses elementos é enaltecido como suficiente à busca pelo sucesso, contudo, por ser baseado na meritocracia, o caminho é desigual: os(as) jovens das classes populares não possuem os mesmos pontos de partida para assegurar o ato de "empreender" como a juventude burguesa. Assim, o fato de não concretizar os lucrativos sonhos vendidos pelo mercado acaba gerando frustração, tendo em vista que a causa do fracasso é projetada aos sujeitos e não ao sistema: que, na verdade, é o autêntico responsável por não sustentar a lógica que promove. Em síntese, é uma "livre" prisão de sonhos baseada na culpabilização das juventudes e no esvaziamento das políticas públicas que poderiam oferecer novos horizontes frente a essa complexa situação.

Quando a liberdade é defendida, atrelada à reprodução de uma lógica de mercantilização integral da vida das pessoas, cria-se uma liberdade neoliberal (SCHEEFFER; CIGNACHI, 2013). Scheeffer e Cignachi (2013, p. 86) afirmam que "uma liberdade que fundamenta o privilégio de uma minoria apenas pode ser uma falácia”. O resultado dessa condição é a intensificação das desigualdades e a submissão irrestrita aos modelos econômicos internacionais, os quais utilizam mão de obra e mercados de países das periferias do capitalismo de forma exploratória. Nisso, a ausência do Estado tem papel determinante, pois

Essa ideologia do empreendedorismo caminha lado a lado com a ausência de políticas públicas. O esvaziamento do Estado, como resultado das políticas neoliberais, faz as políticas e equipamentos públicos serem coisas distantes no cotidiano dos jovens, no que se refere à proposição de soluções às suas questões. (TRI CONTINENTAL, 2020).

Em 2020, devido à pandemia de covid-19, as contradições do neoliberalismo se evidenciaram principalmente nas pessoas em situação de vulnerabilidade social. A partir do alto índice de óbitos registrado nas periferias: "[...] seja no Brasil, periferia mundial; nos estados do Norte e Nordeste, periferias do Brasil; e nos bairros e regiões mais negras, vulnerabilizadas em parte pelo menor acesso aos serviços públicos e estatais." (TRI CONTINENTAL, 2020), foram revelados os impactos da fisiológica ausência de políticas públicas de combate à desigualdade. É perceptível como essa crise afeta de forma imensurável uma parcela da população, enquanto outros grupos se beneficiam deste estado de calamidade?

Na concepção dos neoliberais, o Estado e suas políticas públicas constituem um empecilho para a livre concorrência entre as pessoas, mesmo quando não há igualdade na disputa. Grande parte dos autores que seguem essa ideologia defende que "a intervenção estatal estaria afetando o equilíbrio da

\footnotetext{
$9 \mathrm{O}$ artigo publicado pelo site do Instituto Humanitas (IHU), Por que ricos ficaram mais ricos e a pobreza explodiu na pandemia?, propõe uma discussão sobre o tema da intensificação das desigualdades na pandemia. Para o autor, "diferentes relatórios de organizações internacionais indicam que os milionários ficaram ainda mais ricos durante a pandemia de coronavírus. Os ligados ao setor digital e de novas tecnologias foram os mais beneficiados no período. Ao mesmo tempo, o surto de covid-19 acentua as desigualdades sociais e aumenta a pobreza no mundo, seja nos países desenvolvidos ou nos emergentes". Disponível em: http://www.ihu.unisinos. br/78-noticias/603349-por-que-ricos-ficaram-mais-ricos-e-pobreza-explodiu-na-pandemia. Acesso em: 20 jan. 2021.
} 
ordem, tanto no plano econômico como no plano social e moral, na medida em que tende a desrespeitar os princípios da liberdade e da individualidade, valores básicos do ethos capitalista" (AZEVEDO, 2004, p. 12). Porém, essa perspectiva exime todo o histórico do processo de exploração inerente ao modo de produção capitalista, o qual suprimiu a soberania de diversos países e povos para o beneficiamento de poucas pessoas. Através da invenção da liberdade neoliberal é oportunizada a manutenção das profundas desigualdades, as quais podem vir a ser amenizadas pelo Estado.

Ao conclamar como maligna a intervenção estatal, "[...] acusando as instâncias públicas de serem autoritárias e corruptas, resultando na restrição das liberdades individuais” (AZEVEDO, 2004, p. 11), o neoliberalismo propicia um sucateamento dos valores da democracia. Se os direitos sociais são reconhecidos e garantidos pelo Estado, a produção de ideias anti-estatais provoca uma desconstrução da prática da cidadania e, consequentemente, uma precarização no acesso aos direitos sociais garantidos pela Constituição Federal. Nesse sentido, a "livre" prisão dos sonhos neoliberais cerceia a cidadania, transforma a proteção social em privilégio e mercantiliza a vida dos 99\% (ARRUZA; BHATTACHARYA; FRASER, 2019) em favor de uma minoria que expande suas formas de dominação.

A flexibilização da dignidade em nome de uma ilegítima liberdade desumaniza os sujeitos da forma mais cruel. Os sonhos das juventudes do século XXI são acompanhados por processos de desumanização que, em vez de ampliar horizontes de vida, encaixotam perspectivas junto com todos os direitos presentes na Lei no $12.852 / 2013$. Liberdade haverá, de fato, quando o ideal empreendedor do "indivíduo-empresa" for modificado pelo anseio de construir vida digna sem nem um direito a menos. Ação que só pode ser consumada através da luta coletiva que leve em consideração a interseccionalidade entre classe, gênero e raça (AKOTIRENE, 2019).

\section{Colaboradores podem ser sujeitos de direitos?}

O verbo "colaborar", no dicionário, pode apresentar diversos sentidos que beiram ora a cooperação ora a concorrência. No sistema capitalista, a colaboração inverte a lógica da solidariedade para promover o individualismo: cria-se a figura de sujeitos com protagonismo, engajamento e autonomia que é vendida como se os colaboradores tivessem a mesma parte nos lucros que o detentor do meio de produção. É como se fossem sócios, jamais patrão e empregado. Diante disso, nas relações trabalhistas, a polissemia desse verbo atenua empecilhos, tendo em vista que a lógica do "indivíduo-empresa" gera uma espécie de encantamento pelo fato de colaborar em detrimento de meramente trabalhar.

Assim, as novas relações de trabalho impostas pelo neoliberalismo ludibriam a consciência dos trabalhadores, elaborando novas racionalidades que passam a legitimar que a persistência individual e a fidelidade à empresa são suficientes para angariar o crescimento profissional, econômico e simbólico. Para Dubar (2009),

o sujeito competidor engajado nos projetos da empresa é um sujeito desmantelado, porque não tem mais referências no campo da cidadania, a qual também perdeu valor e legitimidade social. Dessa equação social e política resulta a perda coletiva da legitimação dos porta-vozes dos problemas do trabalho e da sociedade, problemas que passam a ser enfrentados, sobretudo, pela esfera individual. (MARTINS, 2020, p. 101).

A lógica empresarial da "maximização de si" (MARTINS, 2020, p. 101) exige uma competência individual que retira direitos e favorece a desumanização dos(as) trabalhadores(as). Ao olhar a realidade juvenil é possível perceber que o método de exploração aplicado à expropriação de mais-valia ${ }^{10}$ é ainda mais hediondo. 
Baptista (2008) argumenta que os anseios dos(as) jovens ao demandar um trabalho são ligados à emancipação financeira da família e ao desejo de consumir, inserindo-os(as) em empregos associados ao setor terciário da economia. Todavia, com a pandemia de covid-19, diferentemente dos aspectos apontados pela autora, a carência material impôs a massiva incorporação de jovens como bikeboys (ABÍLIO, 2020) ou motoboys do mercado informal. A diminuição da remuneração somada à necessidade de renda levou a uma subordinação involuntária que se deu através da elevação da jornada de trabalho e do custeio dos equipamentos de segurança - que não foi realizado pelas empresas, mas pelos trabalhadores (ABÍLIO et al., 2020).

O cenário de intensificação da informalidade vai em contradição com o "direito à profissionalização, ao trabalho e à renda", que consta no artigo 14 do Estatuto da Juventude. Nesse trecho, descreve que "o jovem tem direito à profissionalização, ao trabalho e à renda, exercido em condições de liberdade, equidade e segurança, adequadamente remunerado e com proteção social" (BRASIL, 2014, p. 17). No entanto, nos últimos anos, é perceptível jovens se submetendo a condições de trabalho contrárias à liberdade, à equidade e à segurança, em circunstâncias cada vez mais precarizadas e sem estabilidade.

Em menos de 10 anos da aprovação da lei que compreende os(as) jovens como sujeitos de direitos é conservado um contexto de privação de condições básicas à dignidade humana. Até então, as pessoas que se localizavam na faixa etária dos 15 aos 29 anos eram compreendidas pelo governo a partir de noções fundamentais sobre dois eixos: a) oportunidades e b) direitos; educação, qualificação e cidadania como oportunidades para adquirir capacidades; mercado de trabalho, crédito, renda, esportes, lazer, cultura e terra como oportunidades para utilizar as capacidades; e a garantia de direitos que acontecia através dos serviços voltados às necessidades básicas para aproveitar as oportunidades à disposição (BAPTISTA, 2008). Hoje, é possível perceber que os direitos são precarizados porque as oportunidades são praticamente inexistentes.

Nesse sentido, a partir do Estatuto da Juventude, foram oficializados de forma legal os direitos da juventude, a fim de não deixá-los para livre interpretação. Também, é um importante documento de referência para a elaboração das políticas públicas de juventude, bem como legitimar as que estavam em andamento. Para garantir esses direitos, e avançar nas proposições colocadas no documento com o intuito de dar dignidade à juventude, a intervenção estatal é uma importante ferramenta. A partir da existência de um documento regulador, abriu-se um leque muito maior para a construção das políticas públicas, principalmente em um cenário onde a intervenção estatal era um dos pontos essenciais para o desenvolvimento do país. Posteriormente,

Com esses princípios o governo federal expõe um quadro onde percebemos os seus principais programas e projetos da política nacional de juventude: PROJOVEM; ProUni; Programa Livro Didático Para o Ensino Médio; Proeja; Programa Brasil Alfabetizado; Projeto Rondon; Soldado Cidadão; Segundo Tempo; Escola Aberta; Pontos de Cultura; Bolsa Atleta; Nossa Primeira Terra e Pronaf Jovem; Programa Juventude e Meio Ambiente; Saúde do Adolescente e do Jovem. (BAPTISTA, 2008, p. 107).

Com base no processo que resultou nas políticas públicas às juventudes, juntamente com uma análise da conjuntura, é possível estabelecer uma relação metafórica com um conceito bem conhecido na área da sociologia da juventude. A moratória social, conceito cunhado por Erikson (1976) em seus estudos sobre o desenvolvimento humano, discorre acerca de um período de suspensão que é vivido durante a juventude. É o momento em que, sem tantas responsabilidades, os(as) jovens vivenciam diversas experiências na busca pelo comprometimento necessário à vida adulta. Depois de muitas críticas que afirmavam que a concepção não levava em consideração as juventudes das classes populares - as quais não viviam a moratória tendo em vista o fato de adentrarem ao mercado de trabalho precocemente -, pode-se afirmar que quem vive a moratória, hoje, no Brasil, são as políticas públicas de juventude e não a juventude em si. 
O Estatuto da Juventude segue em vigor, mas há uma suspensão de sua efetividade na realidade: os direitos estão pendentes e as oportunidades estão em modo de espera. Destarte, essa suspensão ocasiona uma precarização das oportunidades que leva a uma privação de direitos. Com a ausência do Estado, os(as) jovens são socializados(as) a partir da lógica empreendedora que cria excelentes colaboradores e relés sujeitos de direitos que são fiéis às empresas que atuam na manutenção de um sistema que os(as) consome e descarta como se fossem meras mercadorias. Em vez de se compreender como cidadãos-cidadãs construtores(as) da realidade social, são "trabalhadores com múltiplas competências que maximizam-se na corrida para manter-se no emprego, uma corrida produtora de maior individualismo e permeada de uma permanente insegurança, onde nada está garantido" (MARTINS, 2020, p. 101).

Ser "sujeito de direito" não suporta a noção de "colaborador", porque a dignidade reivindicada naquele não é sustentada por este. Diante disso, hoje, mais do que compreender a importância do Estatuto da Juventude em si, é primordial mapear as razões que impedem a consolidação de uma cidadania plena às/aos jovens a partir dele. Conforme evidenciado, romper com as amarras do neoliberalismo é um passo importante que só poderá ser efetivado mediante políticas públicas que garantam a promoção de oportunidades à potencialização de capacidades, viabilidade à utilização destas e uma permanente luta pela garantia dos direitos previstos na legislação.

\section{Transgredir a liberdade neoliberal: uma ação à libertação juvenil}

Aprender a transgredir ${ }^{11}$ as "livres" prisões que são sustentadas pela liberdade neoliberal é uma ação necessária à libertação juvenil. Contudo, é preciso atentar às ilusões que são apresentadas quase que diariamente na vida das pessoas, tendo em vista que o sistema possui estratégias qualificadas para ludibriar enquanto amplia sua dominação. Como citamos durante o texto, na juventude são identificadas três dessas problemáticas envolvendo a disputa ideológica do neoliberalismo: 1) a lógica do "indivíduo-empresa", 2) a violenta flexibilização das regulamentações trabalhistas e 3) os discursos contrários à intervenção estatal.

O primeiro elemento, pautado pela meritocracia que se apoia nos fundamentos do empreendedorismo, é resultado de uma falsa premissa de igualdade na qual o mérito e o esforço próprio seriam suficientes para a ascensão financeira. Nesse ponto, são explícitas as contradições existentes na racionalidade em questão, tendo em vista que as desigualdades sociais não asseguram uma concorrência justa entre as pessoas. Na verdade, o que ocorre é uma disputa desigual que resulta no trabalho precarizado e sem investimentos para seu desenvolvimento e expansão. As consequências desse contexto atravessam a vida de jovens que parcelam ou alugam bicicletas para se tornar entregadores nas empresas de aplicativos como Uber, iFood e Rappi. Expostos aos mais diversos riscos, são corpos superexplorados que passam mais de $8 \mathrm{~h}$ diárias pedalando em vias super movimentadas com o celular na mão, dormindo nas praças para estar sempre à disposição das empresas. É o capitalismo em sua última expressão: a desumanização.

Em consonância com a lógica acima descrita, evidenciam-se as flexibilizações no campo das legislações trabalhistas e o sucateamento da seguridade social. São esses os frutos de um sistema fracassado e falido que intensifica as desigualdades ao inibir o desenvolvimento financeiro dos sujeitos em situação de vulnerabilidade econômica. Em muitos dos casos, sem as regulamentações trabalhistas, os bike-boys, freelancers e trabalhadores autônomos se colocam em condições de

11 Para bell hooks (2013), transgredir é confrontar as estruturas de poder. Na educação bancária, por exemplo, as narrativas dominantes são predominantes e temáticas como sexismo, racismo e luta de classes não são discutidas dentro da sala. Então, aprender a transgredir não significa, necessariamente, desenvolver rebeldia, contudo formar um pensamento autônomo que seja capaz de libertar os(as) estudantes das estruturas que oprimem. Os dominadores são representados na figura do homem, burguês, branco e colonizador. Por isso, a prática da educação libertadora significa se levantar contra a opressão humana. 
trabalho extremamente precarizadas para conseguir um resultado suficiente à sobrevivência. $\mathrm{E}$ quando não atingem as metas que levam ao sucesso, são responsabilizados pelo fracasso imposto pelo modus operandi. Diante do imprevisível, sem muitas perspectivas de futuro, os medos são promovidos e os sonhos são descartados: fato que amplia as frustrações que perpassam a condição juvenil - apesar de ela ser vivida de forma desigual e diversa.

A experiência geracional vivida pelos(as) jovens é inédita e, infelizmente, é marcada pelo abandono. As juventudes pobres, negras, residentes nas periferias das grandes cidades e no campo são as mais atingidas pelo desamparo, situação que amplia as vulnerabilidades. Diante disso, em vez de serem resguardadas as fragilidades que são inerentes ao período, elas são alargadas pela privação dos direitos que deveriam ser garantidos a partir do Estatuto da Juventude. Das possibilidades que poderiam ser gestadas pelas vulnerabilidades juvenis, com o neoliberalismo essa situação toma aspectos absolutamente negativos a qual torna os(as) jovens passivas vítimas em lugar de proporcionar que se desenvolvam enquanto sujeitos, cidadãs e cidadãos. São negados direitos, acessos e possibilidades porque o Estado - elevado ao mínimo - é eximido de sua responsabilidade.

Além do mais, esse esvaziamento da intervenção estatal prejudica quem necessita dos serviços públicos básicos, já que grande parte da população não possui verba para custear o acesso às atividades privadas. Saúde e educação, setores essenciais a um projeto de desenvolvimento nacional, são drasticamente penalizados ${ }^{12}$ por governos que seguem as políticas neoliberais e não respeitam a Constituição Federal - como é o caso da Emenda Constitucional 95, popularmente nomeada de PEC do teto dos gastos públicos e aprovada após o golpe de 2016. Ao avaliar o contexto brasileiro, em contrapartida ao desmonte do Estado, pela vida das juventudes, é urgente que sejam retomados os programas sociais, bem como revogadas as políticas de contingenciamento fiscal. No âmbito governamental, também é necessário que sejam realizadas cobranças mais duras à Secretaria Nacional de Juventude ${ }^{13}$, a qual é simpática à lógica neoliberal e aposta em programas ${ }^{14}$ de incentivo ao empreendedorismo como se o problema do desemprego fosse suprido pela coragem de empreender.

Quando o Estado serve à desumanização, a cidadania é comprometida, fato que gera graves implicações à democracia. Não há como construir um país democrático com uma lacuna na participação de seus cidadãos e suas cidadãs, tendo em vista que, hoje, a maioria da população dedica grande parte do tempo em trabalhos informais no intuito de garantir recursos mínimos à sobrevivência. Em contrapartida, o preço dos bens de consumo se multiplica em um ritmo absurdamente lendo em relação ao aumento do salário mínimo, isso sem contar que a renda de muitas famílias não atinge os R \$1.100. É nesse contexto caótico que estão inseridas as milhões de pessoas que constituem a categoria e vivenciam as consequências de uma condição juvenil forjada pela ampliação da pobreza ${ }^{15}$ e o acirramento das degradantes condições de trabalho. Assim, irrompe a seguinte questão: se os(as) jovens dedicam a maior parte do tempo às longas e deteriorantes jornadas de trabalho, como construirão uma democracia plena?

12 AGÊNCIA Senado. Promulga Emenda Constitucional do Teto de Gastos Públicos. Senado Notícias. Brasília, DF, 2018. Disponível em: https:// www12.senado.leg.br/noticias/materias/2016/12/15/promulgada-emenda-constitucional-do-teto-de-gastos. Acesso em: 28 jan. 2021. 13 Ao pautar as contradições apresentadas pela Secretaria Nacional de Juventude, vale lembrar que foi dado um parecer favorável à redução da maioridade penal que retornou ao debate público em dezembro de 2020. A manifestação foi assinada pela secretária nacional de juventude, Emilly Rayanne Coelho Silva Disponível em: https://noticias.uol.com.br/colunas/leonardo-sakamoto/2020/12/15/ secretaria-de-juventude-da-parecer-favoravel-a-reducao-da-maioridade-penal.htm. Acesso em: 28 jan. 2021.

14 Como é o caso do Programa Horizontes que foi lançado em 2020 que, segundo a Ministra Damares Alves, "Temos esse desafio e a coragem de começar a quebrar paradigmas. O mundo já estava caminhando por esse trilho e a pandemia do novo coronavírus (Covid-19) nos empurrou. O empreendedorismo vem trazer esperança para muitos jovens. Esta é uma alternativa para transformar vidas". Disponível em: https://www.gov.br/mdh/pt-br(as)suntos/noticias/2020-2/outubro/governo-federal-lanca-programa-de-estimulo-aoempreendedorismo-entre-jovens. Acesso em: 28 jan. 2021.

15 Segundo o economista Daniel Duque, sem o auxílio emergencial o Brasil terá mais de 20 milhões em situação de pobreza extrema. Disponível em: http://www.ihu.unisinos.br/78-noticias/606170-sem-auxilio-emergencial-brasil-deve-ter-mais-de-20-milhoes-em-pobreza-extrema. Acesso em: 28 jan. 2021. 
Em relação à noção de juventude, é novamente e negativamente superada a problemática ideia de "jovem como solução", considerando que não há tempo para pensar no futuro da sociedade quando há demandas materiais urgentes no presente. Da mesma forma que precisa ser superada a noção de "jovem como sujeito de direitos" que não se efetivam na prática, caso contrário as juventudes seguirão sendo punidas pelos grandes empecilhos sistêmicos que geram graves problemas hoje e seguirão promovendo adversidades quando essa geração completar 30 anos. Sem a intervenção do Estado brasileiro e a reimplantação das políticas públicas de juventude, esta será a geração do abandono que experimentará impasses em todas as dimensões do desenvolvimento humano.

Com a falta de compromisso das instituições governamentais, algumas organizações de juventude da sociedade civil já vêm pautando essas questões, como é o caso da Pastoral da Juventude que projeta ${ }^{16}$ na celebração de seu Jubileu (2023) o debate acerca da defesa da vida através das Políticas Públicas de Juventude. Ademais, as ações de solidariedade dos movimentos sociais nas periferias são somadas a essas denúncias, como também empenham-se para garantia mínima de direitos para famílias em vulnerabilidade social. Muitas das ações são organizadas por movimentos de jovens ${ }^{17}$, como o Levante Popular da Juventude e as juventudes da Via Campesina, que atuam na entrega de cestas básicas, organização de cursinhos pré-vestibular populares e outras atividades.

Transgredir a "liberdade individual" é um ato que só pode ser realizado de forma coletiva, afinal, "triunfo se não for coletivo é do sistema"18. Diante da privação dos direitos das juventudes, a valorização e o acompanhamento das vivências juvenis é uma forma de desenvolver novas políticas de acesso, que garantam uma efetiva ascensão social de jovens e incentivem sua participação em entidades da sociedade civil e na política institucional. Essa inserção pode facilitar o desenvolvimento de novos programas sociais que sejam coerentes com as demandas da realidade no intuito de movimentar as estruturas injustas que mantêm a opressão.

Hoje é notável como, principalmente, essas organizações sociais (movimentos sociais, pastorais, organizações não governamentais, entre outras) promovem processos educativos que desafiam romper com a manutenção dos valores e costumes incentivados pelo capitalismo neoliberal. Nestes espaços, a individualidade e a competição são combatidos e substituídos por ideias de coletividade e cooperação, com o intuito de desenvolver relações mais humanas. Na mesma medida, essas organizações tornam-se opção para jovens que estão inconformados com a situação política e social do Brasil e avistam nesses espaços alternativas. Transgredir a posição de "colaborador" é mirar outras alternativas e lutar para que elas sejam estruturalmente efetivadas para que a liberdade seja plena: comungada por todas e todos.

16 PJ 50 anos - Rumo ao Jubileu. Disponível em: https://www.pj.org.br/pj-jubileu-50-anos/. Acesso em: 28 jan. 2021.

17 A campanha Nós por nós contra o coronavírus ganha medalha de direitos humanos - Iniciativa do Levante Popular da Juventude foi premiada pelo Sindicato dos Trabalhadores da Fiocruz, no Rio. Disponível em: https://www.brasildefatorj.com.br/2020/08/31/ campanha-nos-por-nos-contra-o-coronavirus-ganha-medalha-de-direitos-humanos. Acesso em: 28 jan. 2012.

18 Devastoprod - O céu é o limite. Participação Rincon, Bk, Rael, Emicida, Djonga, Mano Brown. Disponível em: https://www.youtube. com/watch?v=zMBKjt_hQ|4. Acesso em: 28 jan. 2021. 


\section{Referências}

ABÍLIO, Ludmila Costhek. Uberização e juventude periférica. Desigualdades, autogerenciamento e novas formas de controle do trabalho. Novos Estudos CEBRAP, São Paulo, v. 39, n. 3, p. 579-597, nov. 2020.

ABRAMO, Helena Wendel. Cenas Juvenis: punks e darks no espetáculo urbano. São Paulo: ANPOCS; Scritta, 1994.

ABRAMO, Helena Wendel. O uso das noções de adolescência e juventude no contexto brasileiro. In: FREITAS, Maria Virgínia (org.). Juventude e adolescência no Brasil: referências conceituais. São Paulo: Ação Educativa, 2005.

ABRAMOVAY, Miriam; ESTEVES Luiz Carlos Gil. Juventude, juventudes: pelos outros e por elas mesmas. In: ABRAMOVAY, Miriam; ANDRADE, Eliane Ribeiro; ESTEVES, Luiz Carlos Gil (org.). Juventudes: outros olhares sobre a diversidade. Brasília, DF: Unesco, 2004.

AMADO, Jorge. Capitães de areia. Rio de Janeiro: Record, 2000.

ANDRADE, Carla Coelho de. Entre gangues e galeras: juventude, violência e sociabilidade na periferia do Distrito Federal. 2007. Tese (Doutorado em Antropologia Social) - Instituto de Ciências Sociais, Departamento de Antropologia, Universidade de Brasília, Brasília, DF, 2007.

ANTUNES, Ricardo. Os modos de ser da informalidade: rumo a uma nova era da precarização estrutural do trabalho? Serviço Social e Sociedade, São Paulo, v. 1, n. 107, p. 405-419, set. 2012.

ARrUZZA, Cinzia; BHATTACHARYA, Tithi; FRASER, Nancy. Feminismo para os 99\%: um manifesto. São Paulo: Boitempo, 2019.

AZEVEDO, Janete Maria Lins de. A educação como política pública. 3. ed. Campinas: Autores Associados, 2004.75 p. (Coleção polêmicas do nosso tempo, 56).

AKOTIRENE, Carla. Interseccionalidade. São Paulo: Sueli Carneiro; Pólen, 2019.

BAPTISTA, Tatiane Alves. Família, juventude e neoliberalismo: desafios para a ressignificação do jovem como sujeito de direitos. Libertas: Revista da Faculdade de Serviço Social, Juiz de Fora, v. 8, n. 2, p. 95-110, 2008.

BARBOSA, Lívia. Meritocracia e sociedade brasileira. Revista de Administração de Empresas, São Paulo, v. 54, n. 1, p. 80-85, 2014.

BRASIL. Lei no 12.852, de agosto de 2013. Estatuto da Juventude: Secretaria Nacional de Juventude. Brasília, DF: SNJ, 2014. $48 \mathrm{p}$.

BRASIL DE FATO. Campanha "Nós por nós contra o coronavírus" ganha medalha de direitos humanos: Iniciativa do Levante Popular da Juventude foi premiada pelo Sindicato dos Trabalhadores da Fiocruz, no Rio. 2020. Disponível em: https://www.brasildefatorj.com.br/2020/08/31/campanha-nos-por-nos-contra-o-coronavirus-ganha-medalha-de-direitos-humanos. Acesso em: 28 jan. 2021.

DUBAR, Claude. A crise das identidades: a interpretação de uma mutação. São Paulo: EDUSP, 2009.

ERIKSON, Erik. Identidade, juventude e crise. 2. ed. Rio de Janeiro: Zahar, 1976.

HOOKS, Bell. Ensinando a transgredir: educação como prática da liberdade. São Paulo: Editora WMF Martin Fontes, 2013.

IHU. Conectados globalmente, coletivos juvenis agem na realidade de seus territórios: entrevista especial com Regina Novaes. Entrevista especial com Regina Novaes. 2019. Elaborada por João Vitor Santos. Disponível em: http://www. ihu.unisinos.br/159-noticias/entrevistas/589351-conectados-globalmente-coletivos-juvenis-agem-na-realidade-de-seus-territorios-entrevista-especial-com-regina-novaes. Acesso em: 16 jan. 2021.

MACHADO, Leandro. Dormir na rua e pedalar 12 horas por dia: a rotina dos entregadores de aplicativos. 2019. Publicada na BBC Brasil News. Disponível em: https://www.bbc.com/portuguese/brasil-48304340?ocid=socialflow_facebook. Acesso em: 16 jan. 2021.

MAGNANI, José Guilherme Cantor. Tribos urbanas, metáfora ou categoria? Cadernos de Campo: Revista dos alunos de Pós-Graduação em Antropologia, São Paulo, v. 2, n. 2, 1992.

MARTINS, Eliane de Moura. A identidade dos trabalhadores sob tensão: operário, peão, trabalhador, colaborador. 2020. 157 f. Tese (Doutorado) - Curso de Programa de Pós-Graduação em Sociologia, Universidade Federal do Rio Grande do Sul, Porto Alegre, 2020. Disponível em: https://www.lume.ufrgs.br/bitstream/handle/10183/215253/001118754. pdf?sequence=1\&isAllowed=y. Acesso em: 22 jan. 2021.

MARX, Karl. O Capital: crítica da economia política. In: SINGER, Paul (coord.). Os economistas. v. 2. 2. ed. São Paulo: Nova Cultural, 1985. 
SALGADO, Julia. A cultura empreendedora nos discursos sobre a juventude. Galaxia, São Paulo, v. 25, p. 193-204, 2013.

SCHEEFFER, Fernando. CIGNACHI, Henrique. Liberdade (neo)liberal: que liberdade é essa? Pensamento Plural, Pelotas, v. 12, p. 75-89, 2013.

SOFIATI, Flávio Munhoz. A juventude no Brasil: história e organização. Passages de Paris (APEB-Fr), n. 3, p. 1-14, 2008.

TRANCOSO, Alcimar Enéas Rocha; OLIVEIRA, Adélia Augusta Souto. Aspectos do conceito de juventude nas Ciências Humanas e Sociais: análises de teses, dissertações e artigos produzidos de 2007 a 2011. Pesquisas e Práticas Psicossociais, São João Del-Rei, v. 2, n. 11, p. 278-294, 2016.

TRI CONTINTENTAL. Um olhar sobre juventude e periferia em tempos de CoronaChoque. Dossiê n. 33. 5 out. 2020. Disponível em: https://www.thetricontinental.org/pt-pt/dossie-33-brasil-juventude/. Acesso em: 23 jan. 2021.

Data de submissão: 31/01/2021

Data de aceite: 16/02/2021 